\title{
PENGARUH SUHU DAN KNO 3 TERHADAP PERKECAMBAHAN BENIH DAN HUBUNGAN VARIABEL AGRONOMI AKSESI AREN DALAM MAPANGET
}

\author{
Nyoto Priyono $^{1}$, Susilowati ${ }^{2}$, dan Muhammad Roiyan Romadhon ${ }^{3}$ \\ ${ }^{1}$ Balai Besar Perbenihan Dan Proteksi Tanaman Perkebunan, Jl. Raya Mojoagung No.52, Gambiran Selatan, \\ Gambiran, Kec. Mojoagung, Kabupaten Jombang, Jawa Timur 61482 \\ ${ }^{2}$ Instansi BPSB-Bun Dinas Pertanian Dan Perkebunan Provinsi NTB \\ ${ }^{3}$ Balai Penelitian Tanaman Palma Jl. Raya Mapanget PO BOX 1004 Manado 95001
}

Koresponden Email: roiyannurdin@gmail.com

\begin{abstract}
Abstrak
Aren merupakan tanaman palma yang memiliki banyak manfaat. Benih aren dengan tekstur kulit yang keras menyebabkan sulit berkecambah. Penelitian ini bertujuan untuk mengetahui metode perlakuan benih yang terbaik dan korelasi antar variabel agronomi terhadap munculnya apokol. Penelitian dilakukan di Screen house Balai Penelitian Tanaman Palma Manado pada Bulan April-Juni 2020. Bahan tanaman yang digunakan yaitu aksesi Aren Mapanget (berasal dari Mapanget Kecamatan Minahasa Utara) dengan Rancangan Acak Kelompok (RAK) dengan perlakuan satu Faktor yaitu berupa perlakuan benih secara kontrol, fisik (suhu $\left.50^{\circ} \mathrm{C}\right)$, dan kimia $\left(\mathrm{KNO}_{3} 1,5 \%\right)$ yang diulang sebanyak 3 kali. Hasil Penelitian menunjukkan bahwa perlakuan $\mathrm{KNO}_{3}(1,5 \%)$ memberikan pengaruh positif pada variabel persentase perkecambahan, jumlah benih rusak, dan panjang akar. Korelasi positif terhadap panjang axis embrio yaitu panjang akar dan diameter. Model regresi linear untuk menduga pertambahan panjang axis embrio yaitu: Panjang Axis Embrio=67,47+10.9 x Panjang Akar.
\end{abstract}

Kata Kunci: Aren, Apokol, Suhu, $\mathrm{KNO}_{3}$

\begin{abstract}
Aren is a palm plant that has many benefits. Palm seeds with a hard skin texture make it difficult for the seeds to germinate. This study aims to determine the best seed treatment method and the correlation between agronomic variables on the emergence of the apokol. The research was conducted at the Screen house of the Manado Palma Plant Research Institute in April-June 2020. The plant material used was Aren Mapanget accession (from Mapanget, Minahasa Utara District) with a randomized block design (RCBD) with one-factor treatment, namely in the form of control seed treatment, physical (temperature $\left.50^{\circ} \mathrm{C}\right)$, and chemical $(\mathrm{KNO} 1,5 \%)$ which was repeated 3 times. The results showed that the KNO3 treatment $(1,5 \%)$ had a positive effect on the variable percentage of germination, number of damaged seeds, and root length. The positive correlation to the embryo axis length was root length and diameter. The linear regression model to estimate the increase in the length of the embryo axis is the length of the embryo axis $=67,47+10.9 x$ the root length.
\end{abstract}

\section{Keywords : Aren, Apocol, Correlation, Temperature}

\section{PENDAHULUAN}

Aren (Arenga pinnata) merupakatan tanaman palma yang memiliki bunga dalam satu pohon akan tetapi tidak pada satu tandan. Aren merupakan tanaman tahunan yang memiliki banyak buah. Aren menjadi komoditi palma yang banyak dibudidayakan karena memiliki banyak manfaat. [1] menyatakan bahwa aren memiliki banyak manfaat antara lain bagian batang dapat dimanfaatkan sebagai tepung, buah yang belum matang dapat dimanfaatkan untuk buah kolang kaling, nira aren dapat dimanfaatkan sebagai gula, dan nata de pinna, serta bagian daun digunakan sebagai sapu.

Tanaman yang hidup di hutan dan tumbuh liar mulai banyak diminati oleh pengusaha karena nilai ekonomis yang tinggi. Tanaman aren banyak dibudidayakan untuk kegiatan industri dan kebutuhan sehari-hari. Penanaman aren dimulai dengan melakukan perkecambahan benih. Benih aren dengan kulit yang keras dan tidak menyerap air menyebabkan aren lebih lama berkecambah sehingga menjadi kendala dalam kegiatan budidaya aren. Akibat dari kulit 
aren yang tebal menyebabkan benih mengalami dormansi dan terlambat untuk tumbuh.

Teknik untuk mempercepat benih dengan tekstur kulit yang keras sudah banyak dilakukan sehingga perkecambahan menjadi lebih cepat. Teknik tersebut yaitu skarifikasi baik secara fisik maupun dengan kimia. [2] menyatakan bahwa skarifikasi dengan fisik antara lain suhu, pengamplasan, dan pemotongan, sedangkan skarifikasi dengan kimia dapat menggunakan bahan kimia seperti $\mathrm{KNO}_{3}, \mathrm{H}_{2} \mathrm{SO}_{4}$, dan $\mathrm{HCl}$.

Penelitian ini bertujuan untuk mengetahui metode perlakuan benih yang terbaik dan korelasi antar variabel agronomi terhadap munculnya apokol.

\section{MATERIAL DAN METODE \\ Waktu dan Tempat}

Penelitian telah dilaksanakan pada bulan April - Juni 2020, berlokasi di Screen house Balai Penelitian Tanaman Palma Manado Provinsi Sulawesi Utara.

\section{Bahan dan Alat}

Bahan tanaman yang digunakan yaitu aksesi Aren dalam Mapanget (berasal dari Mapanget Kecamatan Minahasa Utara).

\section{Perlakuan dan Analisis Data Penelitian}

Penelitian menggunakan Rancangan Acak Kelompok (RAK) dengan perlakuan satu Faktor yaitu berupa perlakuan benih secara kontrol, fisik (suhu $50^{\circ} \mathrm{C}$ ), dan kimia (KNO 1,5\%) yang diulang sebanyak 3 kali. Setiap Perlakuan terdapat 15 benih sehingga terdapat 45 satuan percobaan. Pengamatan dilakukan selama 3 bulan pada fase perkecambahan. Pengamatan dilakukan pada pengaruh perkecambahan dan variabel agronomi yang dilakukan dengan pengamatan persentase perkecambahan, jumlah benih rusak, panjang axis embrio, panjang akar, dan diameter akar. Adapun cara pengamatan variabel tersebut antara lain:

1. Persentase Perkecambahan, merupakan variabel untuk viabilitas benih yang dihitung dengan membandingkan jumlah benih yang berkecambah dibagi dengan banyaknya benih yang disemai, dengan rumus:

$$
\begin{aligned}
& \text { Daya Kecambah } \\
& \left.=\frac{\text { Jlh Benih Berkecambah }}{\text { Jlh Benih yg disemai }} \times 100 \% \quad \text {....(Pers. } 1\right)
\end{aligned}
$$

2. Jumlah Benih rusak, banyaknya benih yang tidak tumbuh dan busuk pada setiap perlakuan;

3. Panjang Axis Embrio, diukur dari pangkal benih sampai ujung pertama kali muncul akar dengan menggunakan penggaris;

4. Panjang Akar, diukur dari pangkal apokol sampai ujung akar dengan menggunakan penggaris;

5. Diameter Akar, diukur pada bagian tengah akar dengan menggunakan jangka sorong.

Data yang diperoleh kemudian dilakukan Uji Dunnet antara perlakuan untuk mengetahui perbedaan antar perlakuan terhadap kontrol dengan menggunakan software STAR. Untuk mengetahui hubungan antara variabel maka dilakukan analisis korelasi dan regresi linear sederhana. Menurut [3], menyatakan bahwa hubungan antar karakter agronomi dapat dinyatakan dengan rumus berikut:

$r=\frac{n \sum X Y-\left(\sum X\right)\left(\sum Y\right)}{\sqrt{\left(n \sum(X)^{2}-\left(\sum x\right)^{2}\right)\left(n \sum(Y)^{2}-\left(\sum Y\right)^{2}\right)}} \ldots . . .($ Pers. 2)

Keterangan:

$\mathrm{r}=$ Korelasi antar variabel bebas terhadap hasil

$\mathrm{n}=$ Banyaknya perlakuan

$\mathrm{X}=$ Variabel bebas

$\mathrm{Y}=$ Variabel hasil

Persamaan Garis Regresi Linier sederhana, yaitu:

$Y=a+b X \quad \ldots .$. (Pers. 3)

Keterangan:

$\mathrm{Y}=$ Variabel dependen

$\mathrm{a}=$ Konstanta

$\mathrm{b}=$ Koefisien variabel $\mathrm{X}$

$\mathrm{X}=$ Variabel Independen

\section{HASIL DAN PEMBAHASAN Variabel Agronomi}

Analisis sidik ragam telah dilakukan, diperoleh hasil seperti yang disajikan pada Tabel 1. Berdasarkan Tabel 1, dapat dilihat bahwa bahwa tidak terdapat perbedaan yang nyata antara perlakuan suhu dengan $\mathrm{KNO}_{3} 1,5 \%$ pada jumlah benih rusak, dan diameter akar. Rataan persentase perkecambahan perlakuan $\mathrm{KNO}_{3}$ $1,5 \%$ lebih tinggi dibanding dengan perlakuan kontrol dan meningkatkan daya berkecambah sebesar 26,31\% dibandingkan dengan kontrol. 
[4] menyatakan bahwa konsentrasi $\mathrm{KNO}_{3} \quad 1 \%$ meningkatkan luas permukaan serapan air karena adanya ion $\mathrm{K}^{+}$yang meningkatkan kemampan protoplasma menyerap air. Menurut [5] menyatakan bahwa penggunaan suhu $25^{\circ} \mathrm{C}$ dan $50^{\circ} \mathrm{C}$ meningkatkan daya berkecambah karena pada suhu tersebut kulit biji menjadi tipis sehingga air mudah menyerap. [6] menyatakan bahwa persentase perkecambahan sebagai kunci untuk menilai viabilitas dengan melakukan pendugaan munculnya apokol dan benih yang dorman.

Kategori benih yang busuk ditandai dengan embrio yang sudah tidak berkembang sehingga tidak dapat terjadi pertumbuhan embrio. Benih yang busuk dicirikan dengan embrio yang telah mati. Penyebab benih menjadi busuk karena penanganan perlakukan yang tidak tepat sehingga menyebabkan benih rusak. [7] menyatakan bahwa suhu $50{ }^{\circ} \mathrm{C}$ dapat meningkatkan persentase perkecambahan benih palem dan menurun pada suhu $75^{\circ} \mathrm{C}$.

Panjang axis embrio (apokol) perlakuan $\mathrm{KNO}_{3}$ lebih tinggi dibanding perlakuan lain, karena pemberian perlakuan $\mathrm{KNO}_{3}$ mempercepat munculnya apokol dibanding perlakuan lain. [8] menyatakan penggunaan skarifikasi fisik pada suhu $50^{\circ} \mathrm{C}$ dapat mempercepat perkecambahan. [9] menyatakan pemberian pengaruh suhu dapat mempercepat proses perkecambahan pada benih aren pada umur 44,10 hari. [10] menyatakan bahwa panjang radikula merupakan variabel yang memiliki keeratan dengan kecepatan tumbuh kecambah. Ukuran akar (panjang dan diameter akar).

Tabel 1. Persentase Perkecambahan, Jumlah Benih Rusak, Panjang Dan Diameter Akar Tanaman Aren

\begin{tabular}{lrcc}
\hline \multicolumn{1}{c}{ Variabel } & Kontrol & Suhu $\left(50^{\circ} \mathrm{C}\right)$ & $\mathrm{KNO}_{3}(1,5 \%)$ \\
\hline Persentase Perkecambahan & $37.34 \mathrm{~b}$ & $54.55 \mathrm{ab}$ & $64.00 \mathrm{a}$ \\
Jumlah Benih rusak & $0.00 \mathrm{a}$ & $0.10 \mathrm{a}$ & $0.30 \mathrm{a}$ \\
Panjang Axis Embrio & $22.00 \mathrm{~b}$ & $26.00 \mathrm{ab}$ & $30.45 \mathrm{a}$ \\
Panjang Akar & $6.00 \mathrm{~b}$ & $12.47 \mathrm{a}$ & $12.06 \mathrm{a}$ \\
Diameter Akar & $0.45 \mathrm{a}$ & $0.60 \mathrm{a}$ & $0.50 \mathrm{a}$ \\
\hline
\end{tabular}

Keterangan: Angka yang diikuti huruf kecil pada baris yang sama merupakan hasil uji dunnet pada $\alpha 5 \%$ dibaca secara horizontal pada variabel

\section{Korelasi peubah agronomi}

Analisis korelasi telah dilakukan dan hasilnya disajikan pada Tabel 2. Berdasarkan Tabel 2, dapat dilihat bahwa korelasi antara panjang akar dan diameter dengan panjang axis embrio bernilai positif (1.00). Hal ini menunjukkan bahwa pertambahan panjang akar dan diameter akar akan diikuti pula pertambahan panjang axis embrio. Hal yang sama pada variabel diameter akar dan panjang akar. [11] menyatakan bahwa nilai koefisien korelasi yang mendekati -1 atau +1 memiliki sifat bahwa variabel tersebut memiliki pola hubungan yang semakin erat.

Tabel 2. Korelasi Linier Antar Karakter Kuantitatif Pada Perkecambahan Benih Aren Dalam Mapanget

\begin{tabular}{lccccc}
\hline \multicolumn{1}{c}{ Variabel } & $\begin{array}{c}\text { Persentase } \\
\text { Perkecambahan }\end{array}$ & $\begin{array}{c}\text { Jumlah } \\
\text { Benih rusak }\end{array}$ & $\begin{array}{c}\text { Panjang Axis } \\
\text { Embrio }\end{array}$ & $\begin{array}{c}\text { Panjang } \\
\text { Akar }\end{array}$ & $\begin{array}{c}\text { Diameter } \\
\text { Akar }\end{array}$ \\
\hline Persentase & & & & & \\
Perkecambahan & 1 & & & & \\
Jumlah Benih rusak & 0,79 & 1 & 1 & & \\
Panjang Axis Embrio & 0,98 & 0,99 & $1,00^{*}$ & 1 & \\
Panjang Akar & 0,99 & 0,68 & $1,00^{*}$ & $1,00^{*}$ & 1 \\
Diameter Akar & 0,98 & 0,65 & & & \\
\hline
\end{tabular}


Regresi Linier Sederhana Karakter Panjang Axis Embrio dengan Panjang Akar

Untuk menentukan persamaan regresi linier, data telah diolah dengan software STAR dan didapatkan Koefisien keragaman, R-squared, adjust $\mathrm{R}$-squared, dan nilai koefisien regresi seperti yang disajikan pada Tabel 3. Maka berdasarkan Tabel 3, persamaan regresi linear sederhana yang dihasilkan adalah:

Panjang Axis Embrio

$=67,47+10,9 \times$ Panjang Akar ..... (Pers. 4)

Panjang Akar menunjukkan bahwa jika panjang akar bertambah satu satuan luas maka akan meningkatkan panjang axis embrio sebesar
67,47 satuan luas. Nilai koefisien keragaman tergolong rendah $(16,54)$. Menurut [12] nilai koefisien keragaman rendah berkisar $(0 \% \leq$ $25 \%$ ). Nilai koefisien keragaman yang rendah menunjukkan bahwa tidak ada pengaruh lingkungan sehingga kesalahan pada pengambilan data berkurang. Nilai R-squared $\left(\mathrm{R}^{2}\right)$ sebesar 0,98 menunjukkan bahwa tingkat keberhasilan untuk memprediksi variabel bebas. Nilai R-squared mendekati satu menunjukkan bahwa model tersebut sesuai. Nilai Adjustment R-squared (Adj $\mathrm{R}^{2}$ ) sebesar 0,95 menunjukkan bahwa tingkat keyakinan kebenaran model dengan penambahan variabel bebas tergolong tinggi.

Tabel 3. Koefisien Keragaman, R-squared, Adjust R-Squared, dan Koefisien Korelasi

\begin{tabular}{ccccc}
\hline Koefisien keragaman & R-Squared & $\begin{array}{l}\text { Adjustment R- } \\
\text { Squared }\end{array}$ & konstanta & Koefisien regresi \\
\hline 16,54 & 0,975 & 0,95 & 67,47 & 10,9 \\
\hline
\end{tabular}

\section{KESIMPULAN}

Pemberian Skarifikasi $\mathrm{KNO}_{3} \quad(1,5 \%)$ memberikan peningkatan sebesar $26,31 \%$ lebih tinggi dibanding dengan kontrol pada variabel. Persentase perkecambahan lebih tinggi 5.26\% pada variabel diameter akar. Variabel agronomi yang memiliki korelasi positif terhadap panjang axis embrio yaitu panjang akar dan diameter. Model regresi linear untuk menduga pertambahan panjang axis embrio yaitu Panjang Axis Embrio = 67,47+10,9 $\mathrm{x}$ panjang akar.

\section{DAFTAR PUSTAKA}

[1] Ruslan SM, Baharuddin IT. 2018. Potensi dan pemanfaatan tanaman aren (Arenga pinnata) dengan pola agroforestri di Desa Palakka Kecamatan Barru Kabupaten Barru. $J$. Perennial Vol. 14 No. 1: 24-27.

[2] Ismaturrahmi AI, Hereri H. 2018. Teknik pematahan dormansi secara fisik dan kimia terhadap viabilitas benih aren (Arenga pinnata Merr.). J. Ilmiah Mahasiswa Pertanian. Vol. 3 No. 4: $105-12$.

[3] Singh RK, Chaudary BD. 1979. Biometrical Methods in Quantitative GeneticAnalysis. (New Delhi : Kaylani Publishers)
[4] Hartawan R. 2016. Skarifikasi dan KNO3 mematahkan dormansi serta meningkatkan viabilitas dan vigor benih aren (Arenga pinnata Merr.). $J$. Media Pertanian. Vol. 1 No. 1: 1 - 10

[5] Rumahorbo ARZ, Duryat, AB. 2020. Pengaruh pematahan masa dormansi melalui perendaman air dengan stratifikasi suhu terhadap perkecambahan benih aren (Arenga pinnata). J. Sylva Lestari. Vol. 8 No. 1: 77-84

[6] Aji IML, Sutriono R, Diansyah A. 2020. Pematahan dormansi benih aren (Arenga pinnata (wurmb.) Merr.) pada tingkat kemasakan yang berbeda menggunakan metode perendaman . Jurnal Belantara. Vol. 3 No. 1: 12 - 24.

[7] Nurazizah ZA. 2017. Pematahan dormansi benih palem bajul (Copernica prunifera) dengan Perendaman dalam Air Panas dan Variasi Lama Perendaman Hormon Giberelin. Skripsi. (Kediri: Universitas Nusantara)

[8] Manurung D. Agustina L, Putri P, bangun MK. 2013. Pengaruh perlakuan pematahan dormansi terhadap viabilitas benih aren (Arenga pinnata 
Merr.). J. Agroekoteknologi. Vol. 1 No. 3: 768-82.

[9] Mahayu WM. 2016. Pengaruh kejut suhu terhadap masa dormansi dan viabilitas benih aren (Arenga pinnata Merr.). Buletin Palma. Vol. 14 No. 2: 125 31.

[10] Rahmaniah ME, Erhaka, Heiriyani T. 2018. Aplikasi perlakuan fisik untuk mematahkan dormansi terhadap perkecambahan benih dan pertumbuhan bibit aren (Arenga pinnata Merr.) . JTAM Agrotek Vol. 1 No. 2: 1-8.

[11] Gomez KA, Gomez AA Gomez. 1995. Prosedur Statistik untuk Penelitian Pertanian. Edisi Kedua. (Jakarta : Universitas Indonesia Press): p. 698

[12] Moedjiono, Mejaya MJ. 2014. Variabilitas genetik beberapa karakter plasma nutfah jagung koleksi Balittas Malang. Zuriat. Vol. 5 No. 2: 27-32. 